\title{
Salmonella Gallinarum Virulence in Experimentally-Infected Japanese Quails (Coturnix japonica)
}

\section{-Author(s)}

RC Rocha-e-Silva

WM Cardoso*

RSC Teixeira'

ÁH Albuquerque ${ }^{1}$

RV Horn'

CM Cavalcanti

ES Lopes ${ }^{1}$

VJR Gomes Filho

Students of post grade of Veterinary School of Universidade Estadual do Ceará, Brazil

2 Student of the School of Veterinary Medicine of Universidade Estadual do Ceará, Brazil

\section{Mail Adress}

Corresponding author e-mail address William Cardoso Maciel

Av. Rogaciano Leite, 200 Apt $^{\circ} 1303 \mathrm{BI}$ Tulipe, Bairro Salinas

CEP 60810-000, Fortaleza, Ceará, Brazil

Phone/fax: (085) 32411307 or 31019848 or 99894742

E-mail: william.maciel@uol.com.br and robertarochavet@hotmail.com

\section{"Keywords}

Experimental inoculation, mortality, re-isolation, Salmonella Gallinarum.

\section{ABSTRACT}

Salmonella Gallinarum is the agent of fowl typhoid in poultry and infects mainly adult galliforms, causing significant economic losses in poultry production. Because quails are susceptible to this disease and quail production is becoming increasingly important in Brazil, this study was carried out to evaluate the virulence of Salmonella Gallinarum strain to quails. The inoculum was prepared from $S$. Gallinarum strain resistant to nalidixic acid. Forty eight 16-week-old Japanese quails were randomly distributed in three groups. Before the experiment, cloacal swabs were collected from all birds in order to confirm they were free from Salmonella spp. Cloacal swabs and fecal samples were collected on days 03,06, 09, 12, and 15 post-inoculation. Birds that died during the experiment were submitted to post-mortem examination, and had their organs aseptically collected for bacteriological examination. All eggs produced during the experiment were also examined. The mortality rate recorded during the experiment was $43.75 \%$ (21/48). $S$. Gallinarum was recovered from the organs of the birds that naturally died during the experiment, but the agent was not isolated from the organs of sacrificed birds. No egg sample was positive for Salmonella Gallinarum. It was concluded that S. Gallinarum may be recovered from the organs of experimentally-infected Japanese quails.

\section{INTRODUCTION}

Salmonella spp. genetics allows these bacteria to adapt to many environments, fomites and both mammal and non-mammal hosts (Sanchez-Vargas et al., 2011). The consequences of Salmonella infections depend on inherent pathogen factors, such as virulence, and on the host's capacity of building an adequate immune response to fight the pathogenic agent (Lahiri et al., 2010).

The nature of pathogenicity of Salmonella Gallinarum is multifactorial (Kokosharov, 2003); however, its endotoxin plays an essential role and it is directly linked to the virulence of this microorganism (Kokosharov, 2002). S. Gallinarum naturally infects avian species, which body temperature is $5^{\circ} \mathrm{C}$ higher than that of mammals. It is possible that different environmental stimuli during natural infection influence the host specificity of this bacterium (Pascopella et al., 1995).

Specific Salmonella Gallinarum infection is commonly systemic (Evans, 2011), causing sepsis independently of age, but usually affecting birds older than 3 months. Mortally is usually high and may reach $100 \%$ in some infected flocks (Uzzau et al., 2000). Common symptoms are depression, weakness, ruffled feathers (Freitas Neto et al., 2007), weight loss, 50-70\% drop in egg production (Ezema et al., 2009), prostration, apathy, drooped wings, loss of appetite, dehydration, and greenishyellow to bloody diarrhea (Garcia et al., 2010). Fowl typhoid affects 
RC Rocha-e-Silva, WM Cardoso, RSC Teixeira, ÁH Albuquerque, RV Horn, CM Cavalcanti,

ES Lopes, VJR Gomes Filho
Salmonella Gallinarum Virulence in ExperimentallyInfected Japanese Quails (Coturnix japonica) primarily chickens and turkeys, but pheasants, quails, and guinea-fowl are also susceptible (Shivaprasad, 2000).

Japanese quail production for meat and eggs has expanded in many countries, including Brazil (Minvielle, 2004). Hence, knowledge on the diseases that may affect Japanese quails, including salmonellosis, is essential (Minvielle, 2004). There are literature reports on the isolation of $S$. Typhimurium, $S$. Virchow, $S$. Meleagridis and Group B and $C_{1}$ Salmonella from the cloaca, liver and intestines of Japanese quails (AlNakhli, 2005), S. Typhimurium variant Copenhagen, S. Typhimurium, and $S$. Hadar from live commercial quails and carcasses, and $S$. Paratyphi from the environment (Sander et al., 2001).

This study was carried out to evaluate the virulence of Salmonella Gallinarum in Japanese quails because there is little information on this subject.

\section{MATERIALS AND METHODS \\ Birds}

Forty eight 16 -wk-old Japanese quails ( 24 females and 24 males) were used in the present experiment. Birds were randomly distributed in three groups (G1, G2 and G3) with 16 birds each. Birds were housed per sex in cages, measuring $22 \times 21 \times 16 \mathrm{~cm}$ and organized in pyramid batteries, located at the inoculation facilities of the Center of Ornithological Studies of the State University of Ceará (UECE). Water and feed were supplied ad libitum. Feed did not contain any antibiotics. Birds were not submitted to any vaccination or chemical treatment against parasites. Room temperature $\left(25^{\circ} \mathrm{C}\right)$ was controlled, and a $16 \mathrm{~h}$ light lighting program was applied. The present study was approved by the Committee of Ethics of Animal Use of UECE under protocol number 10244779-9/26.

\section{Bacteriological monitoring before inoculation}

Before the trial started, all birds were checked to ensure they were free from Salmonella spp. The test performed according to Wigley et al. (2001), with some changes, as follows: individual cloacal swabs were collected, immersed in selenite-cystine broth (M025; HIMEDIA®) containing novobiocin $(40 \mu \mathrm{g} / \mathrm{mL}$, SIGMA®) and directly plated (Oh) on brilliant green agar (M016; HIMEDIA®) containing nalidixic acid (100 $\mu \mathrm{g}$ ). Both cloacal swabs and plates were incubated in a bacteriological oven at $37^{\circ} \mathrm{C}$ for $24 \mathrm{~h}$. After incubation, cloacal swab samples that were negative for Salmonella spp. were again plated in brilliant green agar containing nalidixic acid $(100 \mu \mathrm{g})$ and incubated $\mathrm{t}$ $37^{\circ} \mathrm{C}$ for $24 \mathrm{~h}$ to confirm the absence of that bacterium in the experimental birds. In addition, six birds were sacrificed for the collection of liver, spleen, cecum, lung, and reproductive tract (testicle or ovarian follicle) samples. Tissue samples were individually ground and placed in test tubes containing peptone water at $0,1 \%$ at $37^{\circ} \mathrm{C}$ for $24 \mathrm{~h}$, after which an aliquot was transferred to a tube containing selenite-cystine broth with novobiocin $(40 \mu \mathrm{g} / \mathrm{mL})$ and incubated for $24 \mathrm{~h}$ at $37^{\circ} \mathrm{C}$. Samples were then plated in brilliant greed agar with nalidixic acid $(100 \mu \mathrm{g})$ and incubated at $37^{\circ} \mathrm{C}$ for $24 h$.

\section{Inoculum preparation}

The inoculum was prepared using a nalidixic acid resistant Salmonella Gallinarum strain (SGNalr) isolated from chicken (Gallus gallus domesticus) and provide by the Department of Veterinary Pathology of UNESP, Jaboticabal, SP, Brazil. The test performed according to Berchieri et al. (2001), with some modifications, as follows: the bacterial culture was prepared in $5 \mathrm{~mL}$ buffered peptone water at $0.1 \%$ and statically incubated in a bacteriological oven at $37^{\circ} \mathrm{C}$ for $24 \mathrm{~h}$, and The culture was then serially diluted in order to determine the number of colony-forming units (CFU; Miles et al., 1938), after which three different inocula $\left(10^{4}, 10^{5}\right.$, and $10^{6} \mathrm{CFU}$ de Salmonella Gallinarum Nalr/ $\mathrm{mL}$ ) were obtained.

\section{Inoculation}

All birds received via gavage directly in the crop, with the aid of a cannula coupled to a $1 \mathrm{~mL}$ syringe, $0.1 \mathrm{~mL}$ of the inoculum. Group 1 (G1) birds received $5 \times 10^{5} \mathrm{CFU} / \mathrm{mL}$; group 2 (G2), $1 \times 10^{6} \mathrm{CFU} / \mathrm{mL}$; and group 3 (G3), $2 \times 10^{7} \mathrm{CFU} / \mathrm{mL}$

\section{Post-inoculation monitoring}

During the trial, clinical signs and mortality were daily recorded. Dead birds were submitted to gross examination, and their organs collected for microbiological tests for the presence of Salmonella Gallinarum.

Fragments of the liver, spleen, cecum, lungs, and reproductive tract were aseptically collected, individually ground and placed in tubes with peptone water at $0.1 \%$ (7365A; Acumedia $囚)$. Samples were then plated on brilliant green agar with nalidixic acid $(100 \mu \mathrm{g})$ and incubated at $37^{\circ} \mathrm{C}$ for $24 \mathrm{~h}$. Plates were read, and the 
samples negative for Salmonella Gallinarum were transferred to selenite-cystine broth with novobiocin $(40 \mu \mathrm{g} / \mathrm{mL})$, incubated in bacteriological oven at $37^{\circ} \mathrm{C}$ for $24 \mathrm{~h}$, and then plated on brilliant green agar with

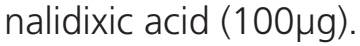

Samples that did not present colonies with typical morphological profile of Salmonella Gallinarum, which are small colonies $(2-4 \mathrm{~mm})$ and have smooth edges and circular shape (Bergey et al., 1994; Gast, 1997), were submitted to an agglutination test using polyvalent $O$ antiserum poly (Difco®).

\section{Cloacal swab samples}

Individual cloacal swabs were collected of all birds (pool of two birds) on 03, 06, 09, 12, and 15 days postinoculation (dpi) and processed as described by Zancan et al. (2000) with some modifications. Individual cloacal swabs were immersed in selenite-cystine broth (M025; HIMEDIA®) containing novobiocin $(40 \mu \mathrm{g} / \mathrm{mL}$, SIGMA®), plated on brilliant green agar containing nalidixic acid $(100 \mu \mathrm{g})$ and then incubated in selenitecystine broth. Both broth and plates were incubated at $37^{\circ} \mathrm{C}$ for $24 \mathrm{~h}$. Cloacal swab samples negative for Salmonella Gallinarum were re-plated on brilliant green agar with nalidixic acid $(100 \mu \mathrm{g})$.

\section{Fecal samples}

Fresh feces from all birds were collected in plastic bags placed under each cage on 03,06, 09, 12, and $15 \mathrm{dpi}$. Samples were weighed and placed in tubes containing $5 \mathrm{~mL}$ peptone water $(1 \mathrm{~g}$ feces: $10 \mathrm{~mL}$ ) and directly plated on brilliant green agar containing nalidixic acid $(100 \mu \mathrm{g})$ and incubated at $37^{\circ} \mathrm{C}$ for 24h. Samples negative for Salmonella Gallinarum were then transferred to selenite-cystine broth with novobiocin $(40 \mu \mathrm{g} / \mathrm{mL})$ and incubated at $37^{\circ} \mathrm{C}$ for $24 \mathrm{~h}$, after which samples were plated on brilliant green agar with nalidixic acid $(100 \mu \mathrm{g})$ and incubated at $37^{\circ} \mathrm{C}$ for $24 \mathrm{~h}$.

\section{Organ sampling}

At the end of the experimental period, birds that were still alive were sacrificed by neck dislocation and liver, spleen, cecum, lungs, and reproductive tract samples were aseptically collected and submitted to bacteriological testing for the presence of Salmonella Gallinarum. Organs were ground, weighed, and individually placed in tubes containing $5 \mathrm{~mL}$ peptone water at $0.1 \%(1 \mathrm{~g}: 10 \mathrm{~mL})$ and subsequently plated on

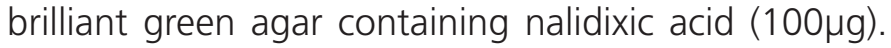
Samples (tubes and plates) were then incubated at $37^{\circ} \mathrm{C}$ for $24 \mathrm{~h}$. Samples that did not produce colonies with the typical morphological profile of Salmonella Gallinarum were transferred to tubes containing selenite-cystine broth with novobiocin $(40 \mu \mathrm{g} / \mathrm{mL})$ to try to increase bacterium recovery. Samples were then incubated at $37^{\circ} \mathrm{C}$ for $24 \mathrm{~h}$ and plated on brilliant green agar containing nalidixic acid $(100 \mu \mathrm{g})$ and incubated under the same previously described conditions.

\section{Procedure for the isolation of Salmonella Gallinarum in eggs}

The eggs produced during the entire experimental period were daily collected, separately placed in quailegg boxes and stored in a cold room at a temperature of approximately $7^{\circ} \mathrm{C}$. At the end of the experiment, all eggs were separated according to production date and experimental group. Eggs were not previously disinfected and were then broken in a sterile beaker (pool of eggs produced during two consecutive days by each group), homogenized (entire egg, including both eggshell and internal content), and placed in a bacteriological oven at $37^{\circ} \mathrm{C}$ for $24 \mathrm{~h}$, as described by Berchieri et al. (2001), with some modifications. After this period, samples were homogenized, collected using sterile swabs, and transferred to selenite-cystine broth with novobiocin $(40 \mu \mathrm{g} / \mathrm{mL})$ and incubated at $37^{\circ} \mathrm{C}$ for $24 \mathrm{~h}$, after which they were plated on brilliant green agar with nalidixic acid $(100 \mu \mathrm{g})$ and incubated at $37^{\circ} \mathrm{C}$ for $24 \mathrm{~h}$.

\section{STATISTICAL ANALYSIS}

Total mortality was compared using non-parametric tests - Chi-square test with Yates correction or Fisher's exact test, as indicated - at 5\% significance level.

\section{RESULTS}

None of the birds evaluated in the pre-inoculation period were positive for Salmonella spp., according to the applied microbiological tests.

Mortality started to be observed after $5 \mathrm{dpi}$ and continued for further six days (Figure 1). Total mortality during the experiment was $43.75 \%$ (21/48 birds), divided as follows: $8.3 \%(4 / 48), 4.16 \%(2 / 48)$, and $31.25 \%$ (21/48) in G1, G2 e G3, respectively.

Within groups $\mathrm{G} 1, \mathrm{G} 2$, and $\mathrm{G} 3$, mortality rates were $25 \%(4: 16), 12.5 \%$ (2:16) e $94.7 \%$ (15:16), respectively, with significant difference ( $p>0.05)$ between G3 and the two other groups. 


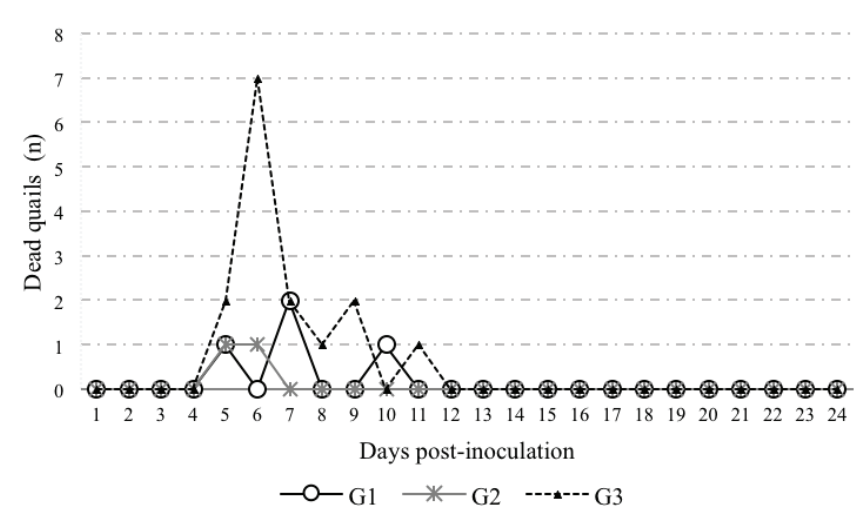

Figure 1 - Daily mortality curve of Japanese quails (Coturnix coturnix japonica) orally infected with Salmonella Gallinarum.

All fecal and cloacal swab samples collected on 03, 06, 09, 12, and 15 dpi were negative for Salmonella Gallinarum. Almost all organs collected from birds that naturally died during the experiment were positive for the bacterium, except for four birds that presented negative cecal samples and one bird that had both negative cecal and reproductive tract samples (Tables 1,2 , and 3). All evaluated organs from quails sacrificed at the end of the experimental period (24 dpi) were negative for the agent.

Table 1 - Recovery of Salmonella Gallinarum from the organs of Japanese quails orally inoculated with $5 \times 105 \mathrm{CFU} / \mathrm{mL}$ (G1) and that naturally died during the experiment.

\begin{tabular}{cccccc}
\hline Birds & Spleen & Liver & Lung & Cecum & $\begin{array}{c}\text { Reproductive } \\
\text { tract }\end{array}$ \\
\hline 02 & + & + & + & + & + \\
\hline 06 & + & + & + & + & + \\
\hline 07 & $\mathrm{NR}$ & + & + & + & + \\
\hline 11 & + & + & + & - & - \\
\hline $\begin{array}{c}\text { Positive } \\
(\%)\end{array}$ & $100 \%$ & $100 \%$ & $100 \%$ & $75 \%$ & $75 \%$ \\
\hline
\end{tabular}

* Birds identified as positive in the plating phase

NR: No result available

Table 2 - Recovery of Salmonella Gallinarum from the organs of Japanese quails orally inoculated with $1 \times 10^{6} \mathrm{CFU} /$ $\mathrm{mL}(\mathrm{G} 2)$ and that naturally died during the experiment.

\begin{tabular}{lccccc}
\hline Birds & Spleen & Liver & Lung & Cecum & $\begin{array}{c}\text { Reproductive } \\
\text { tract }\end{array}$ \\
\hline 40 & - & - & - & - & - \\
\hline 43 & NR & + & + & + & + \\
\hline Positive (\%) & $100 \%$ & $50 \%$ & $50 \%$ & $50 \%$ & $50 \%$ \\
\hline
\end{tabular}

* Birds identified as positive in the plating phase

NR: No result available
Table 3 - Recovery of Salmonella Gallinarum from the organs of Japanese quails orally inoculated with $2 \times 10^{7} \mathrm{CFU} / \mathrm{mL}$ (G3) and that naturally died during the experiment.

\begin{tabular}{cccccc}
\hline Birds & Spleen & Liver & Lung & Cecum & $\begin{array}{c}\text { Reproductive } \\
\text { tract }\end{array}$ \\
\hline 17 & $+^{*}$ & $+{ }^{*}$ & + & + & + \\
18 & + & + & + & + & + \\
19 & + & + & + & + & + \\
20 & + & + & + & - & + \\
21 & + & $+{ }^{*}$ & + & + & + \\
22 & + & + & + & $+*$ & + \\
23 & + & + & + & - & + \\
24 & + & + & + & + & + \\
25 & + & + & + & + & + \\
26 & NR & + & + & + & + \\
27 & + & + & $+*$ & + & + \\
28 & + & + & + & - & + \\
29 & NR & + & + & - & + \\
31 & + & + & + & + & + \\
32 & + & - & - & - & - \\
\hline Positive (\%) & $100 \%$ & $93.3 \%$ & $93.3 \%$ & $62.5 \%$ & $93.3 \%$ \\
\hline
\end{tabular}

* Birds identified as positive in the plating phase NR: No result available

The main clinical sign was apathy. Birds remained quiet in the corner of the cage, with their eyes closed, ruffled feathers, and presented greenish-yellow watery feces, which sometimes contained blood. The main findings at gross examination were enlarged and hemorrhagic liver, enlarged gall bladder, enlarged spleen, hemorrhagic ovarian follicles, and petechial hemorrhages in the intestinal tract.

During the experiment, 170 eggs $(\mathrm{G} 1=65, \mathrm{G} 2=$ $80 ; \mathrm{G} 3=25$ ) were collected, and all were negative for S. Gallinarum.

\section{DISCUSSION}

The high mortality recorded in the present experiment indicates that Japanese quails are sensitive to Salmonella Gallinarum (SG). This result was expected, because scientific literature mentions that SG produces a severe disease, with significant mortality rates in chickens (Compra et al., 2008). Mortality caused by SG may be higher than $80 \%$ in broilers (Paiva et al. 2009), and may reach almost $100 \%$ in inoculated young brown layers (Oliveira et al., 2005). Accordingly, $94.7 \%$ mortality was recorded in G3 in the present experiment.

Although all birds were shown to be sensitive to the pathogen, the administration of inocula with different concentrations caused different mortality rates, in agreement with studies with semi-heavy layers receiving inocula with different CFU levels (Berchieri Jr. et al ., 
RC Rocha-e-Silva, WM Cardoso, RSC Teixeira, ÁH Albuquerque, RV Horn, CM Cavalcanti, ES Lopes, VJR Gomes Filho
Salmonella Gallinarum Virulence in ExperimentallyInfected Japanese Quails (Coturnix japonica)
2001; Garcia et al., 2009). Despite receiving a more concentrated inoculum than G1, mortality in G2 was lower, albeit not statistically significant, demonstrating that increasing SG concentration from $5 \times 10^{5} \mathrm{CFU}$ to $1 \times 10^{6} \mathrm{CFU}$ did not influence mortality rate. On the other hand, the administration of the inoculum with $2 \times 10^{7} \mathrm{CFU}$ resulted in significantly higher mortality in G3 birds compared with $\mathrm{G} 1$ and G3. This was expected due to the high pathogen concentration in that inoculum. Buchholz \& Fairbrother (1992) recorded mortality on 6 and 7 dpi in quails orally inoculated with $10^{5}, 10^{6}$ and $10^{7} \mathrm{CFU} / \mathrm{mL}$ of $\mathrm{S}$. Pullorum, which concentrations are similar to those used in the present study. Those authors also found that the intravenous administration of inocula at $10^{6}$ and $10^{7}$ CFU resulted in mortality on $3 \mathrm{dpi}$. Therefore, the period birds start dying does not depend only on the concentration of the inoculum, but also on the inoculation route.

There are few reports on the evaluation of SG virulence in quails, but studies with chickens are consistent with the results obtained in the present study, particularly relative to the time mortality was recorded, which was between 5 and 11 dpi. Shivaprasad (2000) suggested that birds infected with SG may die within four days after exposure, but they usually start dying five days later and mortality commonly persists for 10 days. Chadfield et al. (2003) orally inoculated young broilers with SG and found that mortality started five days after inoculation. Assoku et al. (1970) also recorded the same time for the beginning of mortality, with a persistence of six further days, as observed in the present study.

Although the results of the present study are consistent with other reports, it must be noted that mortality rates caused by fowl typhoid may considerably vary, and many factors may influence the severity of this disease, such as host's susceptibility (Sato et al., 1997). Freitas Neto et al. (2007) found that semi-heavy commercial layers orally inoculated with approximately $3.3 \times 10^{5} \mathrm{CFU} / \mathrm{mL}$ and that were sensitive to SG started to die on 4 dpi, whereas the SG-resistant birds started dying on $6 \mathrm{dpi}$, demonstrating the bird sensitivity to the microorganism may determine the beginning of mortality. The high mortality recorded in this experiment indicates that quails may be more susceptible to SG than chickens, as the mortality rate related with the concentration of the inoculum was relatively higher than those presented in studies with chickens. Oliveira et al. (2005), working with layers, recorded $94 \%$ mortality, close to that recorded in the present experiment in $\mathrm{G} 3$ birds, when using a SG inoculum at $8.5 \times 10^{8} \mathrm{CFU} / \mathrm{mL}$. Other studies administered higher concentrations than those used in this trial. Barrow et al. (1987) reported 50\% mortality in 2-wk-old broilers orally inoculated with $1.8 \times 10^{\circ} \mathrm{CFU} /$ $\mathrm{mL}$ and Rychlik et al. (1998) observed 60\% mortality in 3 -wk-old layers inoculated with $1.3 \times 10^{9} \mathrm{CFU} / \mathrm{mL}$.

Relative to the presence of SG in fecal and cloacal swab samples, the behavior of this microorganism in inoculated quails was different than that of chickens inoculated with different Salmonella strains. Research studies demonstrated that, when orally inoculated with SG, layers presented positive cloacal swab samples for more than 40 dpi (Oliveira et al., 2005), and those inoculated with Salmonella Entetitidis were positive both in fecal (Nakamura et al., 2004; Ishola et al., 2009), and cloacal swab (Maddadi et al., 2010) samples. Other serotypes, such as S. Pullorum (Berchieri et al., 2001) and S. Typhimurium (Beal et al., 2004), have also been recovered from cloacal swabs of laying chickens submitted to oral inoculation. S. Typhimurium was isolated in cloacal swab samples up to seven weeks post-infection (Beal et al., 2004).

Oliveira et al. (2005) reported that the pathogen may be isolated from feces from dying chickens, and that those with no clinical symptoms that survive the infection may excrete Salmonella for 35 days. Freitas Neto et al. (2007) observed that the agent may be isolated from fecal samples on $7 \mathrm{dpi}$ in semi-heavy layers. In the present experiment, only the organs of the quails that died were positive for SG; according to Beer (1998), the microorganisms present in the animal may significantly replicate after death, which may have allowed SG isolation in the present experiment. On the other hand, SG was not recovered from the organs of birds that survived until the end of the experiment ( $21 \mathrm{dpi})$. It is possible that these birds were able to overcome the infection because, in addition of presenting negative microbiological results, they were apparently healthy, consuming feed and water and producing eggs. Consistent findings were obtained with inoculated and sacrificed chicks: at the end of the experiments, it was not possible to recover SG from their liver, spleen, and ceca (Barrow et al., 1987; Jones et al., 2001), and the birds that survived were apparently healthy (Bumstead \& Barrow, 1993).

The birds that died during the experiment presented classical fowl typhoid symptoms. Birds remained quiet in the corner of the cage, with their eyes closed, ruffled feathers, and presented greenish-yellow watery feces, which often contained blood. The presence of blood in the feces indicates sepsis, which causes gastrointestinal 
hemorrhages and ulceration of the intestinal wall (Chappell et al., 2009).

In the present study, all analyzed egg samples were negative for SG, in agreement with previous studies using experimental infections (Berchieri Jr. et al, 2000; Berchieri Jr. et al, 2001; Oliveira et al, 2005). The vertical transmission of SG occurs easier in poultry strains that are genetically resistant to fowl typhoid.

Although Salmonella is able to penetrate the egg, there are other important extrinsic factors that may interfere in transmission, such as bacterial strain, temperature, humidity, number of microorganisms, and storage conditions (Messens et al., 2005). Some authors assert that eggs produced by SG-infected layers may not present any contamination (Oliveira et al., 2005), differently from layers that carry Salmonella Pullorum (SP) and may vertically transmit this agent through infected eggs due to the quantitative increase of SP in the reproductive tract during sexual maturation. It was found that gonadal hormones may aid the transport of infected macrophages to the reproductive system; however, the mode of SP transmission to the eggs has not been elucidated yet (Wigley et al., 2001).

\section{CONCLUSIONS}

Salmonella Gallinarum is virulent for Japanese quails and the mortality it causes is possibly influenced by the concentration of inoculated bacteria. SG may be recovered from the liver, spleen, cecum, lungs, and reproductive tract of experimentally-infected quails; however, inoculated birds may not show any clinical symptoms or shed the inoculated SG strain.

\section{ACKNOWLEDGEMENTS}

The authors thank Coordenação de Aperfeiçoamento de Pessoal de Nível Superior (CAPES) for funding this study and the Laboratory of Ornithological Studies (LABEO/FAVET/UECE) team for their support.

\section{REFERENCES}

Al-Nakhli HM. Occurrence of Paratyphoid Infection Among japanese quails (Coturnix coturnix japonica) in Saudi Arabia. Journal of Bio-Science, 2005; 12(1):59-66

Assoku KG, Penhale WJ, Buxton A. Haematological changes in acute experimental Salmonella Gallinarum infection in chickens. Journal of Comparative Pathology 1970; 80(3):473-485.

Barrow PA, Simpson JM, Lovell MA, Binns MM. Contribution of Salmonella Gallinarum large plasmid toward virulence in fowl typhoid. Infection and Immunity 1987; 55(2):388-392.
Beal RK, Wigley P, Powers C, Hulme SD, Barrow PA, Smith AL. Age at primary infection with Salmonella enterica serovar Typhimurium in the chicken influences persistence of infection and subsequent immunity to re-challenge. Veterinary Immunology and Immunopathology 2004; 100(3-4):151-164

Beer J. Doença infecciosa em animais domésticos. 1 ed, São Paulo, SP 1998.

Berchieri Jr. A, Murphy CK, Marston K, Barrow PA. Observations on the persistence and vertical transmission of Salmonella enterica serovars Pullorum and Gallinarum in chickens: effect of bacterial and host genetic background. Avian Pathology 2001; 30(1):221-231.

Berchieri Jr. A, Oliveira GH, Pinheiro LAS, Barrow PA. Experimental Salmonella Gallinarum infection in light laying hen lines. Brazilian Journal of Microbiology 2000; 31(1):50-52.

Bergey DH, Holt JG, Krieg NR. Bergey's: manual of determinative bacteriology. 9 ed. Baltimore: W. \& Williams; 1994.

Buchholz PS, Fairbrother A. Pathogenicity of Salmonella Pullorum in northern bobwhite quail and mallard ducks. Avian Diseases 1992; 36(2):304-312

Bumstead N, Barrow P. Resistance to Salmonella Gallinarum, S. Pullorum and S. Enteritidis in Inbred Lines of Chickens. Avian Diseases 1993; 37(1):89-93

Chadfield MS, Brown DJ, Aabo S, Christensen JP, Olsen JE. Comparison of intestinal invasion and macrophage response of Salmonella Gallinarum and other host-adapted Salmonella enterica serovars in the avian host. Veterinary Microbioogy 2003; 92(1-2):49-64.

Chappell L, Kaiser P, Barrow P, Jones MA, Johnston C, Wigley P. The immunobiology of avian systemic salmonellosis. Veterinary Immunology and Immunopathology 2009; 128(1-3):53-59.

Evans EE. Zoonotic diseases of common pet birds: psittacine, passerine, and columbiform species. Veterinary Clinics of North America: Exotic Animal Practice 2011; 14(3):457-476

Ezema WS, Onuoha E, Chah KF. Observations on an outbreak of fowl typhoid in commercial laying birds in Udi, South Eastern Nigeria. Comparative Clinical Pathology 2009; 18(4):395-398.

Freitas Neto OC, Arroyave W, Alessi AC, Fagliari JJ, Berchieri Jr. A. Infection of Commercial Laying Hens with Salmonella Gallinarum: Clinical, Anatomopathological and Haematological Studies. Brazilian Journal of Poultry Science 2007; 9(2):133-141

Garcia KO, Santana AM, Freitas Neto OC, Simplício KMMG, Alessi AC, Berchieri Jr. A, Fagliari JJ. Experimental infection of commercial layers using a Salmonella enterica sorovar Gallinarum strain: blood serum components and histopathological changes. Brazilian Journal of Veterinary Pathology 2010; 3(2):111-117

Garcia KO, Berchieri Jr. A, Santana AM, Freitas-Neto OC, Fagliari JJ. Experimental infection of commercial layers using Salmonella enterica serovar Gallinarum strain: Leukogram and serum acute-phase protein concentrations. Brazilian Journal of Poultry Science 2009; 11(4):263270.

Gast RK, Porter Jr. RE, Holt PS. Applying tests specific yolk antibodies to predict contamination by Salmonella Enteritidis in eggs from experimentally infected laying hens. Avian Diseases 1997; 41(1):195202.

Ishola OO. Effects of challenge dose on faecal shedding of Salmonella Enteritidis in experimental infected chickens. African Journal of Biotechnology 2009; 8(7):1343-1346. 
Jones MA, Wigley P, Page KL, Hulme SD, Barrow PA. Salmonella enterica serovar Gallinarum Requires the Salmonella Pathogenicity Island 2 Type III Secretion System but Not the Salmonella Pathogenicity Island 1 Type III Secretion System for Virulence in Chickens. Infection and Immunity 2001; 69(9):5471-5476.

Kokosharov T. Acid tolerance, bile salts and serum resistance of Salmonella Gallinarum from hens. Veterinarski arhiv 2003; 73(5):277-283.

Kokosharov T. Clinical and hematological effects of Salmonella Gallinarum endotoxin in cockerels. Veterinarski arhiv 2002; 72(5):269-276.

Lahiri A, Lahiri A, lyer N, Das P, Chakravortty D. Visiting the cell biology of Salmonella infection. Microbes and Infection 2010; 12(11):809-818.

Maddadi MS, Hassanzadeh M, Bozogmehrifard M, Shojaei $H$, Yazdani A, Karimi V, Barin A. Study on two inoculation routs of Salmonella Enteritidis in abilities to colonize in internal organs and to contaminate of eggs in broiler breeder hens. International Journal of Poultry Science 2010; 9(3):254-258.

Messens W, Grijspeerdt K, Herman L. Eggshell penetration by Salmonella: a review. World's Poultry Science Journal 2005; 61(1):71-86.

Miles, A.A.; Misra, S.S.; Irwin, J.O. (1938). The estimation of the bactericidal power of the blood. J. Hyg. (Lond), 38 (6), p.732-749.

Minvielle $F$. The future of japanese quail for research and production. World's Poultry Science Journal 2004; 60(4):500-507.

Nakamura M, Nagata T, Okamura S, Takehara K, Holt PS. The Effect of Killed Salmonella Enteritidis vaccine prior to induced molting on the shedding of S. Enteritidis in laying hens. Avian Desease 2004; 48(1):183-188.

Oliveira GH, Berchieri Jr. A, Fernandes AC. Experimental infection of laying hens with Salmonella enterica sorovar Gallinarum. Brazilian Journal of Microbiology 2005; 36(1):51-56.

Paiva JB, Penha Filho RAC, Argüello YMS, Silva MD, Gardin Y, Resende F, Berchieri Jr. A, Sesti L. Efficacy of several Salmonella vaccination programs against experimental challenge with Salmonella Gallinarum in commercial brown layer and broiler breeder hens. Brazilian Journal of Poultry Science 2009; 11(1):65-72.
Pascopella L, Raupach B, Ghori N, Monack D, Falkow S, Small PL. Host restriction phenotypes of Salmonella Typhi and Salmonella Gallinarum. Infection and Immunity 1995; 63(11):4329-4335.

Purchase C, Picard J, McDonald R, Bisschop SPR. A comparison of the oral application and injection routes using the onderstepoort biological products fowl typhoid vaccine, its safety, efficacy and duration of protection in commercial laying hens. Journal of the South African Veterinary Association 2008; 79(1): 39-43.

Rychlik I, Lovell MA, Barrow PA. The presence of genes homologous to the K88 genes faeH and fael on the virulence plasmid of Salmonella Gallinarum. FEMS Microbiology Letters 1998; 159(2):255-260.

Sanchez-Vargas M, Abu-El-Haija MA, Gómez-Duarte OG. Salmonella infections: An update on epidemiology, management, and prevention. Travel Medicine and Infectious Diseases 2011; 9(6):1-15.

Sander J, Hudson CR, Dufour-Zavala L, Waltman WD, Lobsinger C, Thaye SG, Otalora R, Maure JJ. Dynamics of Salmonella Contamination in a Commercial Quail Operation. Avian Diseases 2001; 45(4):1044-1049.

Sato, Y., G. Sato, L. Tuchili, G. S. Pandey, A. Nakajima, H. Chimana, and H. Sinsungwe. 1997. Status of Salmonella Gallinarum- Pullorum infections in poultry in Zambia. Avian Diseases 1997;41(2):490-495.

Shivaprasad HI. Fowl typhoid and pullorum disease. Office International des Epizooties, Scientific and Technical Review 2000; 19(2):405-424.

Uzzau S, Brown DJ, Wallis T, Rubino S, Leori G, Bernard S, Casadesús J, Platt DJ, Olsen JE. Host adapted serotypes of Salmonella enterica. Epidemiology \& Infection 2000; 125(2):229-555

Wigley $\mathrm{P}$, Berchieri Jr. A, Page $\mathrm{KL}$, Smith $\mathrm{AL}$, Barrow PA. Salmonella enterica serovar Pullorum persists in splenic macrophages and in the reproductive tract during persistent, disease-free carriage in chickens. Infection and Immunity 2001; 69(12):7873-7879.

Zancan FT, Berchieri Jr. A, Fernandes AS, Gama NMSQ. Salmonella investigation in transport boxes of day-old birds. Brazilian Journal of Microbiology 2000; 31(3):230-232. 
